\title{
Collective citizenship: From citizenship and mental health to citizenship and solidarity
}

\author{
Neil Quinn ${ }^{1}$ (1) | Billy Bromage ${ }^{2}$ | Michael Rowe ${ }^{2}$
}

${ }^{1}$ Centre for Health Policy, School of Social Work and Social Policy, University of Strathclyde, Glasgow, UK

${ }^{2}$ Yale Program for Recovery and Community Health, Department of Psychiatry, Yale School of Medicine, New Haven, Connecticut, United States

\section{Correspondence}

Neil Quinn, Centre for Health Policy, School of Social Work and Social Policy, University of Strathclyde, Lord Hope Building, 141 St James Road, Glasgow G4 OLT, UK.

Email: neil.quinn@strath.ac.uk

Funding information

Connecticut Department of Mental Health and Addiction Services; Marie SkłodowskaCurie, Grant/Award Number: 690954

\begin{abstract}
Although the concept of citizenship is a widely used theoretical framework within political philosophy, its use in the field of mental health remains underexplored. Within this context, citizenship emphasises the social inclusion and participation of people who are marginalized and offers a more social and relational view of services and support for people with mental health problems than has been common in mental health systems of care. At the same time, however, the citizenship approach has operated in the context of systems of care in the United States that favour highly individualized conceptions of, and approaches to, care, and these systems of care operate in the social and political context of highly individualized concepts of the citizen. In this article building on the work of other citizenship scholars, we argue that a collective form of citizenship, grounded in the 5 Rs framework, holds the individual and collective in creative tension. Furthermore, the paper applies this model to the domain of mental health, where people are treated in individualistic ways and experience marginalisation, making the collective dimension imperative and promoting participation, empowerment and the contribution for social change to people with mental health problems. Our theoretical framework of collective citizenship, while geared toward the needs of persons with mental health problems, also contributes to recent citizenship theory on the inclusion of marginalized, stigmatised, and excluded groups. We illustrate the application of this approach through an ethnographicparticipant observation case study of a collective citizenship group with which we are associated.
\end{abstract}




\section{KEYWORDS}

citizenship, collective, mental health

\section{1 | INTRODUCTION}

This paper aims to advance our understanding of the concept of citizenship, in particular the idea of collective citizenship within the context of mental health. In doing so, it draws on a wide range of literature on citizenship to describe the 5 Rs model developed by the authors to understand and address exclusion faced by people with mental health problems. This theoretical innovation will then be applied to a collective citizenship programme within a mental health context (FACE) to enable us to understand the components of collective citizenship. The paper concludes by drawing out the key implications of this approach for research, policy, and practice.

\section{IHEORY AND APPLICATION}

\section{1 | The concept of citizenship-Traditions and tensions}

The application of the concept of citizenship is relatively novel in the mental health field and its use as a framework for the social inclusion of people with mental illnesses has been shaped and informed by general citizenship theory. One of the key tensions in the citizenship literature is between individualism and collectivism. Janoski (1998) focuses on two important theoretical traditions: Marshall's (1964) developmental model of legal, political and social rights balanced with taxes, military, and other service obligations to the state, and the Tocquevillian/Durkheimian model of solidarity and general exchange, represented in part by civic participation and volunteerism (Durkheim, 1893/1933; Tocqueville, 1994). Janoski distinguishes between substantive citizenship (the ways in which stigmatised groups gain rights and recognition as citizens) and formal citizenship (the ways in which aliens become naturalised citizens with accompanying rights and obligations). He further distinguishes between passive legal and social rights and obligations and the practice of rights and obligations in one's community, including political action and dissent.

One of the key ways in which the individual rights of citizens are realised is through collective social movements and social struggles. This conceptualisation can be linked to the work of Engin Isin, who has written extensively about claims to citizenship and social struggles (Isin \& Nielsen, 2008). Isin argues that we have witnessed the birth of new "acts of citizenship" for individuals coming together as both organised and spontaneous protests and the emergence of "activist" international courts, as well as new media and social networking as sites of struggle (Isin, 2009). This work, in turn, relates to recent shifts in citizenship theory toward opening up citizenship opportunities for individuals experiencing marginalisation (Werbner \& Yuval-Davis, 1991).

Hartley Dean offers a useful framework for addressing distinctions among different forms and aspects of citizenship theory and the tension between individualism and collectivism. The French Revolution ideal of liberty, equality, and fraternity, he argues, is unattainable in practice, as the demands of the three conflict with each other. Two different "solutions" are liberal-contractarian and republican-solidaristic citizenship. The liberal or contractarian citizenship tradition privileges the demand for liberty or individual freedom and seeks a compromise whereby individuals enter into a social contract with the state for the protection of their liberties and rights, while accepting corresponding responsibilities to the state. Republican-solidaristic citizenship, by contrast, privileges fraternity and social solidarity and subordinates the sovereignty of the individual to the need for mutual support and cohesion. This approach is concerned with realising citizenship through collective advocacy and struggle (Dean, 2004). The dichotomy between liberal and republican models of citizenship is underpinned by different views of the human condition. Proponents of the liberal model would take the view that society is comprised of self-interested individuals who require a 
contractual arrangement by which individual freedoms must be traded for social order through state regulation. On the other hand, proponents of the republican model would take the view that human subjects are vulnerable and require collective structures to survive (Dean 2004).

Dean also draws out the distinction between systemic assumptions that privilege the role of social and political structures, on one hand, and agential assumptions that privilege the role of either individual or collective human action, on the other. Systemic assumptions frame welfare rights in terms of how needs should be met. Agential assumptions frame welfare rights as the outcome of struggle or negotiation over interpreted needs. Duffy (2010) argues for a citizenship that assures social justice based on the dignity of all persons and the values of diversity and "personalisation"-the participation of peers in designing, implementing, and running the services they receive.

Acknowledging social and political structures requires engagement with the politics of neoliberalism. Neoliberalism and its structures shape and contort how citizenship is attained, as it alienates people who stand beneath the top of the economic hierarchy (Carroll \& Sapinski, 2016). The relationship between neoliberalism and citizenship has been described as "technologies of citizenship" (Cruikshank, 1999). In her study of postwelfare-state governance in the United States, Cruikshank (1999) illustrates how the most effective forms of domination often go undetected, with power hidden from view and presenting no visible targets for opponents to attack or resist: "this is a manner of governing that relies not on institutions, organised violence or state power but on securing the voluntary compliance of citizens" (Cruikshank, 1999, p. 4). To secure compliance, "technologies of citizenship" are mobilised to enlist the autonomy, interests, and wills of citizens.

We have defined citizenship as people's access to and possession of the 5 Rs of rights, responsibilities, roles, resources, and relationships that society offers its members, and a sense of belonging in society that is validated by others (Clayton, O'Connell, Bellamy, Benedict, \& Rowe, 2013; Rowe, 2015). The 5Rs were chosen to encompass two commonly held understandings of citizenship, which reflect the tension between individualism and collectivism. The first is the individual focus on legal citizenship, conferring legal and civil rights on citizens along with citizen's corresponding responsibilities to the state such as serving in the military in times of conscription, paying taxes, obeying laws, and serving on juries. The second is the more collective civic-social-participational aspects of citizenship, including relationships with one's fellow citizens as equals in the context of possessing socially valued roles. The critical $\mathrm{R}$ of resources can be described as a hinge for both state- and civic-oriented Rs, as their possession undergirds people's orientation to both the state and civic-community life.

The 5 Rs framework ensures a coherence between individual and collective understandings of citizenship, holding the individual and collective in creative tension. The Rs of rights and responsibilities in our citizenship framework align most closely to Marshall's relationship of the individual citizen to the state. The $\mathrm{R}$ of relationships aligns closely with civic-participational views of membership in society, whereas the $\mathrm{R}$ of resources, as above, underlies the capacity of people to practice meaningful citizenship. The $\mathrm{R}$ of roles aligns with the civic-participational view of citizenship but is also associated with the capacity to exercise one's individual citizenship rights. The 5Rs align with Dean's work, combining aspects of democratic-liberal (rights-based in relation to the state) and republican-solidaristic (roles and relationships) conceptions of citizenship. Our applied framework responds to Cruickshank's call for "new technologies of citizenship" to counter the neoliberal conception of the docile citizens' of hidden powers that shape and monetize them. The theoretical innovation of this paper is in applying an approach that holds the individual and collective in creative tension to the domain of mental health, where people are treated in individualistic ways and experience marginalisation, making the collective dimension imperative.

\section{2 | Conceptualising citizenship as participation in society}

Our citizenship practice and research were initially inspired by the third author's work with a well-resourced mental health outreach team to people who were homeless. Outreach workers found that placing clients in housing involved, for many, isolation and loneliness in their apartments, ostracism by neighbours, lack of knowledge of how to manage apartment living, and consideration of "moving back" into homelessness. Although these outreach workers helped 
individuals access services and support, what they could not do was to help their clients become neighbours, community members, and citizens (2015, third author).

This conceptualisation, however, although it directs attention to participation in society over participation in managing one's systems and maintaining personal stability, challenges highly individualistic mental health systemic approaches in the United Kingdom and United States. This is related to the influence of neoliberalism, which has been charged with creating social divisions (Springer, 2016) and devaluing community resources by turning people and their public institutions into commodities for economic gain rather than viable actors and resources for collective benefit (DeFilippis, Fisher, \& Shragge, 2010; McKnight \& Block, 2012). The neoliberal political context has resulted in the development of individualized services. Our response to this is the development of a "collective citizenship" approach employing the building blocks of the 5 Rs and a sense of belonging. Collective citizenship does not neglect the needs and aspirations of its individual members. In fact, it supports Dean's "relational" and Sylvestre's (2017) "personalisation" emphases in citizenship practice, while at the same time providing group experience and cohesion that individuals require as social beings.

Collective citizenship is characterised by group membership and consensus-based group decision making in contrast to leadership based on expertise, position, or degree. In collective citizenship, power rests within the group rather than being possessed by or, if shared at all, portioned out by a paid professional. Professionals can have important roles in collective citizenship efforts but as common-cause partners, not as designated leaders of it. Collective citizenship does not ignore and is not intended to replace the individual's unique citizenship needs, preferences, and growth, or the individual's right to autonomy and self-determination, as exemplified in the independent living movement. Rather, it enables to motivate the individual to realise these rights through relationships within the group, including mutual support, and through the process of taking collective action (van Zomeren, 2013). In fact, achieving the social aims of independent living requires collective action (Hasler, 2003). This framework resonates with the work of Beresford (2013), who argues for user-led initiatives in which service users are supported to come together in service user only initiatives. Beresford (2013) identifies new collective forms of involvement that service users have developed, which are accessible and take account of their disability or illness and include direct action and protest.

\section{3 | COLLECTIVE CITIZENSHIP: A CASE EXAMPLE}

Our citizenship work and study has involved explicit modelling and testing of citizenship in practice, such as though the Citizens Project, an individual and group intervention whose components were based on, and attempted to translate into empirical practice, the 5Rs of citizenship (including classes based on the 5Rs and support for achieving a sense of belonging in society, such as through community valued role projects; Rowe et al, 2007). In other cases, however, we have supported the development of projects guided and supported by the citizenship approach but allowing for experimentation by the agents involved. Our case example of collective citizenship practice-FACE-is an example of the latter form of citizenship intervention and evaluation.

FACE, as named by its members, began in 2015 with two conversations with people receiving services at a psychosocial rehabilitation centre in New Haven, Connecticut. The conversations were led by the second author, a social worker trained as a community organiser, and a certified peer specialist. The conversation at the first meeting evolved in response to two questions: "What are ways to get involved in your community?" and "What are things that need to change in your community?" The second conversation built on the themes identified from the first. Each conversation lasted roughly an hour. Based on the relationships and momentum generated during those conversations, a group of six decided to meet regularly to discuss how to engage with the community together. Many of the individuals involved in the first and second large group meetings decided not participate after the initial idea generation phase. 
The group initially met at the rehabilitation centre, then at a coffee shop in a nearby bookstore, as group members decided they wanted a nonmental health, community-based site for the meetings. This step was identified by members as essential to speaking and acting freely and without oversight from mental health professionals and to attract new members not associated with the mental health system. Over the next 3 years, the group has grown to roughly 20 members, with 10-12 people attending a given meeting at the coffee shop or community event.

FACE represents an approach to promoting citizenship that provides support for individual members to take collective action. It does this in three ways: (a) providing an opportunity for people to get involved in community life in ways they have not been able to previously as individuals; (b) adding to, and sometimes enhancing, the ways in which people are involved in community life; and (c) co-producing a forum for both discussing community-related issues that members encounter as individuals and discussing strategies in the collective space for addressing them. Some members have limited experience with community building and community activism outside of their experiences with FACE, whereas others see FACE as augmenting their current community activities, sometimes even enhancing their status as community activists in other domains.

We contend that the collective action, power-shifting focus of FACE, in which individuals play an active role in social change, more closely resembles community organising approaches than traditional behavioural health interventions (DeFilippis et al., 2010; Labonte, 2012). Community organising has been defined as "collective action by community members drawing on the strength of numbers, participatory processes, and indigenous leadership to decrease power disparities and achieve shared goals for social change" (Staples, 2012, pp. 1-2). This collective approach also aligns with an increasing focus in policy making on co-production (Sorrentino, Sicilia, \& Howlett, 2018). Coproduction is defined as "when you as an individual are involved as an equal partner in designing the support and services you receive" (Clark 2015). This has been driven by people with lived experience pushing for greater control over their care. This includes an interest in "collective co-production," in which groups and communities work together and benefits of co-production are enjoyed by the entire community (Bovaird, Van Ryzin, Loeffler, \& Parrado, 2015). FACE's community organising emphasis operationalizes a key recommendation in an earlier paper on citizenship in which service providers had to "step back when necessary and cede part of their power" (Rowe, Kloos, Chinman, Davidson, \& Cross, 2001).

When initiating the group (although not its collective nature, which has evolved), the second author has intentionally limited his social worker role to recruiting, scheduling meetings, taking and distributing meeting notes, communicating with members between meetings, and facilitating connections to community organisations. He has not provided case management or clinical support to any FACE members. Such support would clash with group norms, because relationships within FACE are not predicated on the service model dichotomy of provider and recipient and members strive to share authority equitably.

The ongoing role of the certified peer specialist has been twofold: First, inviting people to the group, reminding members about meetings, in some cases meeting people to walk to meetings or events together; and second, setting an example, through her voice and role, for others as they find their own voices and roles as community activists. Both the second author and the peer specialist facilitated the creation of a space in which the formal mental health system was intentionally kept at arm's length, in order for people affiliated with that system to explore identities and affiliations other than service recipient.

This approach is consistent with U.K. community development literature on nondirective community development (Popple, 1995) in which control resides with community members rather than professionals. It also aligns with several strains of community organising tradition in the United States, especially women-centred community organising (Stall \& Stoecker, 1998).

Women-centred community organising is clearly reflected in FACE's approach to the social worker's, certified peer specialist's, and other members' roles. Stall and Stoecker (1998) describe this approach as beginning with relationships formed in small groups and focused on the "expanded private sphere" of home, local community, and extended family networks to which many women, particularly women of colour, have historically been relegated due to the exclusionary public domains and structures dominated by men (Stall \& Stoecker, 1998). The organiser's role in 
women-centred organising, with roots in the caretaking role in the home and the expanded private sphere, is to facilitate the process of building skills, self-confidence, and trust among group members in an environment of shared decision making in which each member takes personal responsibility, participates in defining mutual interest, shares power, and co-designs action strategies (Ohmer \& DeMasi, 2009; Stall \& Stoecker, 1998; italics ours).

This approach to community organising is not exclusively carried out by or intended to empower women but rather embraces an approach based on empowerment of all members through a mutually supportive, small group environment (Stall \& Stoecker, 1998). Stall and Stoecker suggest that the qualities of taking the time to focus on process, on the contributions of all members, and on consensus building are traditionally attributed to women, in contrast to the male-dominated confrontational and "zero sum" organising championed by Saul Alinsky (Stall \& Stoecker, 1998). Additionally, the women-centred organiser identifies participants in community improvement work whom other organisers might overlook (Ohmer \& DeMasi, 2009). This feminist approach to community organising is more relational and focuses on bridging the small group to larger community groups as a central component of community organising campaigns to influence those who hold power (Ohmer \& DeMasi, 2009; Stall \& Stoecker, 1998).

\section{4 | METHOD}

The aim of this study was to gain an in-depth understanding of the meaning and activities of collective citizenship in practice through the lens of the tension between individual and collective needs. To achieve this, we employed an ethnographic approach. Ethnographic research is the study of people in naturally occurring settings using methods to capture their social meanings and ordinary activities, with the researcher's direct participation the setting and activities of study (Bryman, 2016). A defining feature of ethnographic research is its reliance on direct observation and insider perspectives (Padgett, 2017). Ethnography is underpinned by the idea that knowledge of the social world is acquired from intimate familiarity with day-to-day practice and the meanings of social action (Bryman, 2016).

Meeting notes were written by the second author at all FACE meetings (approximately 60 to date). Meeting notes, rather than anthropological or sociological field notes, were gathered as FACE is structured as a collective community project rather than a research project. The second author recorded discussions among group members in a notebook while also participating in the discussions. He shared meeting notes with members of the group as a vehicle for reminding members about priorities that had been set in previous meetings or about steps required to complete a shared project. In this way, meeting notes added value to the group and members retained a level of ownership of the information they had generated collectively.

Criteria for membership in the group are a desire to build community and form relationships with other members. Members are not required to have experiences with mental health problems to join the group. Family members, friends outside of the mental health system, neighbours, and others are encouraged to attend. Most of FACE's 20 plus current members, however, do have personal experiences with serious mental health problems, and many have faced other life disruptions including incarceration, substance abuse, and homelessness. Still, group members are explicit in their desire that mental health not be the identifying feature of the group, as doing so would undermine FACE's identity and purpose as a community group with community members. Beyond the initial recruiting described in the previous section, the second author and the peer support specialist recruited new members by describing FACE to people in other citizenship-related interventions and by speaking with people in their own social networks. The latter included people both experiencing and not experiencing mental health problems. The group draws inspiration from community organising ideas that identify relationships between and contributions of individuals across identity groups as integral components of successful community building (Walter \& Hyde, 2014). The authors acknowledge that this approach to inclusion and exclusion criteria presents a challenge to established methods of qualitative analysis.

Because the group is not exclusively designed for people with significant life disruptions, group members selfdisclose their experiences through conversations during meetings, often while drawing a parallel to someone who is 
still experiencing a similar life disruption such as homelessness, community re-entry from prison, use of illegal substances, or mental health difficulties.

After two and a half years of meetings, a research plan, including analysis of meeting notes, was developed. Initial themes were identified using an inductive approach to thematic analysis of meeting notes (Braun \& Clarke, 2006). Our approach to analysis was informed by our theoretical framework. In particular, we analysed the data through the lens of the relationship between individualism and collectivism within citizenship discourse to ensure a theoretically informed empirical analysis. The authors discussed and revised the initial themes and how they fit together to reveal the tension between individual and collective needs and the overall story of FACE (Braun \& Clarke, 2006). Using the revised themes, the meeting notes were reviewed a second time, and finalised themes were developed. Additionally, the second author analysed transcripts from qualitative interviews conducted with 15 FACE members and identified quotes related to themes developed during analysis of the meeting notes. The interviews are part of another research project currently underway. Written consent was obtained from all interviewees by the research assistant who conducted the interviews. Both analysis of meeting notes and of qualitative interviews were included in the research plan approved by the university's institutional review board.

As noted previously, FACE is an example of a citizenship project not explicitly based on the 5 Rs and belonging but of one developed in the context of an overarching framework of citizenship. Therefore, a final step in our analysis, following development of our final themes, we subjected each to the question of its relationship to our citizenship definition.

\section{5 | FINDINGS}

Following the analysis, three major key themes emerged: defining the purpose, mutual support, and collective action. The presentation of results contains quotes from participants.

\section{1 | Defining the purpose}

The first theme to emerge from the observations of the FACE group was that of defining the purpose of the group. Discussions about how the group might operate in a community milieu helped it to find its bearings in the early days, when members struggled to define a direction in the absence of a predetermined hierarchy or decision-making structure. The process of planning for community engagement fostered conversations about the overarching purpose of the group. At times, this involved a painstaking process of multiple discussions and disagreements, sometimes through shared attention to granular details. Throughout the process, FACE members balanced the value of pushing forward their own ideas with that of developing group consensus on given issues:

It's grown a lot because at first people used to think that their idea was the correct way instead of listening to mine ... it took a while, you know, we had to learn how to listen to each other, but now we do. We don't ... it used to be arguing. If somebody did argue it's so out of place now. So I don't think that would happen. I think someone would stop and "no, you've got to listen, even if you don't agree." (FACE participant, male, in his early 60s)

The group's decision-making process is that no significant action is taken collectively if one member strongly disagreements with it. For example, coming up with the name of the group was on the agenda at more than a dozen meetings over more than a year. Members considered how each version of the name might reflect its purpose to community partners. Candidates included Belonging, Understanding, Dignity and Belonging through Mindful Engagement, initially a contender until a member pointed out that it might be perceived as "egocentric." While naming the group was a labour-intensive approach, it was also, in retrospect, a vehicle building respect and camaraderie among 
members. Group members continuously shape the purpose of the group through discussion at meetings and activities they decide to pursue in other community settings, though not without discomfort at times. However, the relatively unstructured nature of the decision-making process can lead to what some members see as a disjointed, frustrating series of conversations to get to a shared understanding:

So, the only thing, I mean, can we become a cohesive group? We can, but it's going to take a lot of work on all parts. You know, but it's just the cohesion that I don't see. Every ... sometimes things are scattered, and so I'm just looking for that cohesion. Because I feel like if we're going out there to represent encouraging community or help uplifting a community, we have to be encouraging and uplift each other. (FACE participant, female, in her mid-40s)

One member shared a similar frustration but qualified the occasionally "chaotic and unproductive" decisionmaking process of FACE with a suggestion of its greater purpose for the group culture:

The downside of that is that the meetings could be somewhat chaotic and unproductive at times and I think people just had to kind of get comfortable with that. We couldn't always, we could have a couple of agenda items and we could do our best to get through them, but we had to let go of the idea that we were ever going to be this efficient machine. Because part of what the whole thing meant was just to be together. So, there are probably, I guess I come away thinking there are probably more efficient ways of doing community organising but something like FACE has just such a, there was just something so humanistic and meaningful about people being together in this way. (FACE participant, male, in his early 30s)

FACE has intentionally not identified as a group for people with mental health problems as a group for addressing mental health problems, although members have included mental health under an umbrella of issues being addressed in its meetings and in community settings. FACE is focused on building community generally, not through the lens of mental health, stigma, or marginalisation:

Because it's just not people that has mental health in this meeting. And we're not even talking about mental health, so a lot of our stuff that we talk about, don't have nothing to do with mental health. So, I think that's very powerful that we're not coming there to be talking about "Oh poor me, we're the victim" because it's about other people. (FACE participant, female, in her mid-50s)

Some members, however, initiate discussions about stigmatising behaviour that they witness in the community and struggles they face with feeling disempowered as clients in mental health programmes. One group member shared his concern that a day programme "discards people" who do not follow the rules rather than acknowledging that it takes people a while to recover. Another group member shared his frustration that he was similarly discarded when programme staff misunderstood comments he made to another participant, falsely claiming he had broken the agency's conduct policy and suspending him from services. One member described the difference between mental health programme settings and FACE:

Once you're in a mental health center there's that control. You can't really say what you want because you're in that controlled setting. [FACE is] outside of the mental health [centre]. So, people that have mental health, we don't worry about repercussions coming down if we say what we need to say. And nobody, you know, blaming us or judging us. (FACE participant, female, in her mid-50s)

In these scenarios, FACE members describe the experience of control by service providers as an obstacle to their progress. Although FACE has not identified its objective as increasing members' agency in the mental health 
programme milieu, it might achieve that by facilitating empowerment and eschewing control both within the group and in the broader community settings in which members engage.

Regarding the discomfort expressed by the FACE member quoted above on the group's lack of cohesion and lack of control in the FACE setting compared with mental health services, this is related at least in part to an essential element of collective citizenship, that recipients of services become accustomed to the expertise, power, and decisionmaking authority of programme staff and administrators, thus experiencing discomfort when power and decision making are placed in their hands, instead. This shift can be disorienting for people, requiring the support of fellow collective community members.

The Rs of relationship and valued roles and a sense of belonging appear to be at work in the theme of defining purpose. These elements occur in and through the development and ongoing work of maintaining a group of empowered individuals and an empowered group. FACE members are developing collective power, through a process that sometimes involves ceding some individual power. Members in professional roles-the social worker and certified peer specialist-must be vigilant to adhere to this process as well, not succumbing to the usual power dynamic of service providers when difficulties in the group process seem to "call" for their intervention to save the day.

\section{2 | Mutual support}

The group has considered and in many cases compensated for the practical difficulties that individual members encounter. In one member's case, impending homelessness and its likely impact on his ability to remain active in the group led to the group rallying around him, helping him fill out a housing application and advocating for and with him in a meeting with his case manager. In such ways, group members collectively help each other with some of the same economic and social problems they themselves face or have faced. This support was not an intentional feature of group development but an outgrowth of the relationships formed in the group. It mirrors the decision-making process in that the group does not move forward with other topics until individual members' needs have been recognised and heard:

Because if they have a problem and they bring it to the meeting, they've got help there. They talk it out amongst each other ... So, I think it don't matter what your problem is, it could be mental, physical, you could just come and talk about it. You've got to get better. (FACE participant, male, in his early 60s)

On the other hand, in spite of the group's dedication to supporting all its members, FACE has significant limitations in addressing the multiple struggles some members experience. A member was unable to participate in some aspects of the group due to limitations associated with being homeless, which were beyond the group's current resources or ability to address:

Well I would feel even better once I get housing, because I'm homeless. And to be able to function within the group, you know. I missed last Friday. They had a meeting, and I usually try to be at every meeting. (FACE participant, female, in her mid-60s)

FACE meetings provide a venue for members to mutually examine frustrations or questions related to community living, such as access to public resources or events in local and national politics. Members may come to a meeting struggling with a situation they encountered in the community or heard about on the news. They can rely on other group members to listen and support them with such struggles. FACE provides a forum for such discussions and appears to increase members' sense of hope for addressing community-related concerns, given its expressed focus on active, collective community building. 
At FACE we talked about the problems in the community and how we can be able to organize, you know, and kind of like address some of the things that concern us. (FACE participant, female, in her mid-50s)

The $\mathrm{R}$ of relationship, along with belonging, may be the most relevant of the citizenship definitional elements embodied in this theme, most notably in the fact that the FACE group must be maintained by its members separately from other supporting structures people may have to draw on. The R of resources is also relevant to the way in which mutual support has taken shape, with FACE members sharing information about housing and low-cost or free food, among other community resources.

\section{3 | Collective action}

FACE members are collective problem-solvers rather than individual recipients of advice from mental health care professionals. They generate courses of action together, rather than having to choose from a predetermined menu of programmes created by mental health professionals. They decide who enters the group, how intragroup conflicts will be resolved, and with which community organisations FACE will partner. In addition, they determine the roles they will assume in a given environment, rather than having such decisions made by others.

Many members see themselves as active community builders. Power rests in the hands of group members rather than in the hands of professionals who are assigned to serve their needs. FACE members are not observers, attendees, or "consumers" of services. They have created murals with adults and children at neighbourhood festivals in two local neighbourhoods, volunteered annually at an event to pack groceries at a food pantry, collaborated on several projects with a neighbourhood association, and joined a local antihunger coalition led by people experiencing poverty themselves who are campaigning against cuts to food welfare.

[An] organization may say, "hey, we need help with the holiday", or "we got something going on over here". We're right there. I mean, you know, we went to the festival in the community. And while we're there we meet new people, you add new people, and it's an impact. Everything we do is an impact. (FACE participant, male, in his early 50s)

An example that highlights several aspects of FACE's unique approach to community engagement is its involvement in an annual festival in the West River neighbourhood of New Haven. The second author passed along an invitation from festival organisers for FACE to get involved in 2016. FACE members accepted the invitation and spent several months planning the details of their participation, including materials needed and roles individual members might play-assisting festival planners with setup, greeting festivalgoers, recruiting people to come to the mural, and organising and handing out materials. Initially, although there was consensus on FACE participation in the festival, there was no consensus on the nature and details of that participation. Conversations across multiple meetings were required, and ideas were often revisited and revised before the group reached consensus on a plan. At times, the second author or the peer specialist advised other group members on how impending or actual stalemates might be resolved through shared decision making. The group decided to facilitate the creation of a mural by festivalgoers, based on the themes of community and recovery, replicating with the public the collective approach of the group by working with community members to create the mural based on ideas that those community members brought to the task.

Like when I first started, they made like a big mural and had everybody sign it. And I was surprised, you know, you could put down anything on that mural that you wanted. And they put down stuff like what they were missing from their community. And everybody got together on that. And I think we have six of them now, they're all full. And so, people are interested in sharing what's on their mind and what they're missing from their community. So, our group is making an impact. (FACE participant, male, in his early 60s) 
Irregular, sparse public transportation options on the weekend, along with some members not having enough money to bring food to supplement the limited food offered at the festival, presented barriers to some members' participation in the festival. Other members offered suggestions and resources, including information on bus routes, and pooled resources beyond the minimal budget the community organiser had for snacks and water. On the day of the festival, FACE members shared responsibility for facilitating creation of the mural, which received positive feedback festival attendees and planners. Festival planners invited FACE to facilitate another mural-making activity the following year.

The Rs of rights and roles and the sense of belonging, present in other themes, are not only paramount here but have an active, collective, and political nature that was identified as such by participants in the process of creation of the group. FACE members exercise their right to self-determination by deciding how and when they will take on projects with other community residents and groups. Inherent in this approach is the right to be a member of the community, and to actively co-produce community activities, despite marginalizing messages to the contrary. Associated with these rights, FACE members create opportunities for belonging in the communities in which they interact as a group, as well as belonging within the micro-community they create among one another.

\section{6 | DISCUSSION}

The findings from this study inform our understanding of and our argument for collective citizenship. Citizenship theory and practice has traditionally focused on securing the rights of the individual within society. Collective citizenship integrates community and structural dimensions of citizenship, including the role of collective advocacy and challenging power structures that disempower and discriminate against people with mental health problems. Our collective citizenship framework derives from integration of ideas from citizenship theory and practice along with other strands of literature including community organising and social movement literature. This discussion will identify the components of collective citizenship that emerge from the study, in particular relating this to Dean's (2004) model of citizenship, which is a particularly useful framework for situating the concept of collective citizenship within the broader citizenship literature.

Collective citizenship, as exemplified in the FACE study, is defined by its focus on the collective rather than the individual for people with mental health problems. This develops conceptualisations of citizenship consistent with Dean's (2004) republican-solidaristic citizenship, which emphasises the importance of social solidarity in achieving citizenship through collectively organised mechanisms for mutual cooperation and support. FACE challenges a dominant focus on the individual in the mental health care system by placing its focus on group development of norms, structures and supports, and activities. There was evidence of strong peer-to-peer support among group members, who were united through their common experience of marginalisation. There were many instances of group members helping each other with challenging problems, contributing to the development of strong bonds between group members. Although the group values individual goals and needs, it moves forward collectively.

Focus on the collective promotes participation and empowerment of people experiencing marginalisation and links with the agential assumptions within Dean's (2004) framework that privilege the role of human action in achieving citizenship. Participation and empowerment involves people experiencing marginalisation being actively involved in the struggle or negotiation over their interpreted needs (Dean, 2004). In FACE, individuals played an active role in shaping services by generating a course of action together rather than selecting from a predetermined menu of programmes created by someone else. To achieve this, a shift in power from social service providers to community members with lived experience of marginalisation had to occur. In keeping with the women-centred community organising approach (Stall \& Stoecker, 1998), trusting relationships within the group and with community partners have been formed, and these provide a strong foundation for continued community work and potential social and political action in the future. This process links with what Janoski (1998) calls participation rights, involving individual and group rights to participate in decision making, and aligns with community organising and social movement 
principles of promoting participation of people with a shared concern for taking power and control to achieve social change.

Collective advocacy aligns with both solidaristic and agential notions of citizenship, given its focus on collectively action to secure citizenship and based in the idea that rights embody collective goals. The individual has the right to pursue his or her own needs but also has duties towards others. For Dean, the good or active participating citizen is a champion of collective cause and the rights they espouse (Dean, 2004). It is argued that citizenship work needs to focus on securing the collective rights of marginalised groups.

Over the past year, some FACE members have joined a local antipoverty organisation through contacts made by the second author and certified peer specialist, indicating that direct activism toward structural change is an additional role for a subset of the group's members. As new members of the local organisation, FACE members have helped to shape its objectives, speaking at a rally about their personal experiences and demands, and attending a meeting with a federal legislator about food security policy where they were featured guests. This process fits well with solidaristic notions of citizenship (Dean, 2004), underpinned by the values of community organising, which support informed collective citizenship. Collective advocacy promotes recovery, generally seen as an individual journey, at a collective level.

Ultimately, collective citizenship needs to be about securing social change and is consistent with the citizenship of "popular resistance," which is agential in being based on the possibility of human action, and solidaristic in that it is undertaken by people as a collective entity (Dean, 2004). Dean's argument that the approach of resistance through everyday practices and discourse resonates links Foucault's (1979) argument that resistance is integral to power, as power is relational and vested in the entire network of human relationships, depending not upon a single oppositional relationship but a multiplicity of points of resistance (Dean, 2004). In the absence of social movement and collective action approaches, citizenship work risks being confined to individualised mental health services. Despite distinct trajectories in their theoretical development, social movement and citizenship paradigms converge at the point where social movements are viewed as collective forms of political citizenship (Van Der Heijden, 2014).

Collective citizenship challenges the "othering" processes of "economic formations and formulations of neoliberalism" (Mitchell, 2016, p. 125), in which the many are relegated to the status of "subcitizens" or "surplus populations" and the few possess "dominant," "privileged," or "elite" citizenship, and in which elites define normative and desirable behaviour, further entrenching the othering of individuals seen as not deserving full citizenship status (England \& Ward, 2016). It is in this context that marginalised people, including persons with mental health problems, must exercise their citizenship by acting collectively to address their marginalisation, negative stereotyping, stigma, and discrimination and promoting the dignity and rights of people who have experienced marginalisation.

\section{7 | CONCLUSION}

Collective citizenship in the context of practice and research in the United States adds a new dimension to citizenship theory and practice, which has the potential to be replicated in other countries. Its contribution to the field of community mental health is that of pointing to a shift from the individual with mental distress as a consumer citizen free to exercise in a neoliberal marketplace to the individual's involvement in collective efforts and "causes" in which rights embody collective goals. Collective citizenship argues for and supports the right to social participation, common cause, and belonging among those who are disadvantaged by economic exploitation or personal circumstances.

Collective citizenship can contribute to a comprehensive strategy for helping people with life disruptions who have experienced marginalisation to achieve fuller citizenship through addressing structural and individual challenges through collective agency. Despite the promise of the model, however, much remains to be learned about the mechanisms for achieving it in practice, including additional research on collective citizenship initiatives. One mechanism that is particularly important to recognise is the professional assistance role in developing solidarity, particularly in 
creating independence from traditional professional health personnel control. Given a key focus of this approach to citizenship is promoting the participation and empowerment of people facing life disruptions, this also suggests that further research should be directed by people with lived experience of marginalisation. A community-based participatory approach that enables people with lived experience of life disruptions take control over the research agenda, with support and involvement of traditional researchers as needed, is likely to enhance the possibility that research findings will generate and promote social and political change through challenging the often-exclusionary nature of research and the broader political system for people experiencing marginalisation.

As a final note, we wish to note that collective citizenship and our argument for it here are not intended to denigrate or deny the importance of more individualized forms of "citizenship works." Colleagues on our research team, for example, have developed a practical tool, based on the $5 \mathrm{Rs}$, for use by case managers and clinicians in the provision of citizenship-oriented care for individuals receiving mental health care. It is not only possible but likely that, as citizenship-oriented care moves forward, individuals receiving such care will also be participating in collective citizenship projects. The Citizens Project, discussed previously, has providing a mix of (mainly) individual- and collectively focused support, with positive results from a randomized clinical trial comparing it with persons receiving current mental health care (Clayton, O'Connell, Bellamy, Benedict, \& Rowe, 2013). In addition, participation in FACE appears to have supported some members' community connection making both outside of FACE group. Collective citizenship approaches, we believe and predict, will enhance and enrichen the repertoire of the citizenship framework in its efforts to support the social inclusion and full participation of individuals with mental health problems in society.

\section{FUNDING INFORMATION}

This project received funding from the European Union's Horizon 2020 research and innovation programme under the Marie Skłodowska-Curie Grant 690954.

This article was written in part with the support of the Connecticut Department of Mental Health and Addiction Services.

\section{ORCID}

Neil Quinn (D) https://orcid.org/0000-0003-3361-7552

\section{REFERENCES}

Bovaird, T., Van Ryzin, G., Loeffler, E., \& Parrado, S. (2015). Activating citizens to participate in collective co-production of public services. Journal of Social Policy, 44(1), 1-23. https://doi.org/10.1017/S0047279414000567

Braun, V., \& Clarke, V. (2006). Using thematic analysis in psychology. Qualitative Research in Psychology, 3, 77-101.

Bryman, A. (2016). Social research methods (5th ed.). London: Oxford University Press.

Carroll, W. K., \& Sapinski, J. P. (2016). Neoliberalism and the transitional capitalist class. In S. Springer, K. Birch, \& J. MacLeavy (Eds.), The handbook of neoliberalism (pp. 39-49). New York, NY: Routledge.

Clayton, A., O'Connell, M. J., Bellamy, C., Benedict, P., \& Rowe, M. (2013). The citizenship project, part II: Impact of a citizenship intervention on clinical and community outcomes for persons with mental illness and criminal justice charges. American Journal of Community Psychology, 51, 114-122.

Cruikshank, B. (1999). The will to empower: Democratic citizens and other subjects. Ithaca, NY: Cornell University Press.

DeFilippis, J., Fisher, R., \& Shragge, E. (2010). Contesting community: The limits and potential of local organising. New Brunswick, NJ: Rutgers University Press.

Duffy, S. (2010). The citizenship theory of social justice: Exploring the meaning of personalisation for social workers. Journal of Social Work Practice, 24(3), 253-267.

England, K., \& Ward, K. (2016). Theorizing neoliberalism. In S. Springer, K. Birch, \& J. MacLeavy (Eds.), The handbook of neoliberalism (pp. 50-60). New York, NY: Routledge.

Isin, E. (2009). Citizenship in flux: The figure of the activist citizen. Subjectivity, 29, 367-388. https://doi.org/10.1057/sub. 2009.25 
Isin, E. F., \& Nielsen, G. M. (2008). Acts of citizenship. European Journal of Migration and Law., 10, 466-469. https://doi. org/10.1163/157181608X380237

Janoski, T. (1998). Citizenship and civil society: A framework of rights and obligations in liberal, traditional, and social democratic regimes. Cambridge, UK: Cambridge University Press.

Labonte, R. (2012). Community, community development, and the forming of authentic partnerships: Some critical reflections. In M. Minkler (Ed.), Community organising and community building for health and welfare (3rd ed.) (pp. 95-109). New Brunswick, NJ: Rutgers University Press.

Marshall, T. H. (1964). Class, citizenship and social development. Chicago, IL: University of Chicago Press.

McKnight, J., \& Block, P. (2012). The abundant community: Awakening the power of families and neighborhoods. San Francisco, CA: Berrett-Koehler Publishers, Inc.

Mitchell, K. (2016). Neoliberalism and citizenship. In S. Springer, K. Birch, \& J. MacLeavy (Eds.), The handbook of neoliberalism (pp. 118-129). New York, NY: Routledge.

Ohmer, M. L., \& DeMasi, K. (2009). Consensus organising: A community development workbook: A comprehensive guide to designing, implementing, and evaluating community change initiatives. Thousand Oaks, CA: Sage Publications, Inc.

Padgett, D. K. (2017). Qualitative methods in social work research. Thousand Oaks, CA: Sage.

Popple, K. (1995). Analysing community work: Its theory and practice. Milton Keynes: Open University Press.

Rowe, M. (2015). Citizenship and mental health. New York, NY: Oxford University Press.

Rowe, M., Kloos, B., Chinman, M., Davidson, L., \& Cross, A. B. (2001). Homelessness, mental illness and citizenship. Social Policy Administration, 35, 14-31. https://doi.org/10.1111/1467-9515.00217

Sorrentino, M., Sicilia, M., \& Howlett, M. (2018). Understanding co-production as a new public governance tool. Policy and Society, 37(3), 277-293. https://doi.org/10.1080/14494035.2018.1521676

Springer, S. (2016). The violence of neoliberalism. In S. Springer, K. Birch, \& J. MacLeavy (Eds.), The handbook of neoliberalism (pp. 153-163). New York, NY: Routledge.

Stall, S., \& Stoecker, R. (1998). Community organising or organising community? Gender and the crafts of empowerment. Gender \& Society, 12(6), 729-756.

Staples, L. (2012). Community organising for social justice: Grassroots groups for power. Social Work with Groups, 35(3), 287-296.

Sylvestre, J. (2017). The contributions of the concept of citizenship to housing practice, policy, and research. In J. Sylvestre, G. Nelson, \& T. Aubry (Eds.), Housing, citizenship, and communities for people with serious mental illness: Theory, research, practice, and policy perspectives (pp. 212-231). New York, NY: Oxford University Press.

Van Der Heijden, H.-A. (2014). Handbook of political citizenship and social movements. Cheltenham: Edward Elgar Publishing.

Walter, C. L., \& Hyde, C. A. (2014). Community building practice. In M. Minkler (Ed.), Community organising and community building for health and welfare (3rd ed.) (pp. 78-94). New Brunswick, NJ: Rutgers University Press.

Werbner, P., \& Yuval-Davis, N. (1991). Women and the new discourse of citizenship. In N. Yuval-Davis, \& P. Werbner (Eds.), Women, citizenship and difference (pp. 1-31). New York, NY: Zed Books.

How to cite this article: Quinn N, Bromage B, Rowe M. Collective citizenship: From citizenship and mental health to citizenship and solidarity. Soc Policy Admin. 2019;1-14. https://doi.org/10.1111/spol.12551 